\title{
O DIREITO À CIDADE E A PARTICIPAÇÃO POPULAR: UMA DISCUSSÃO NECESSÁRIA A PARTIR DOS CONCEITYS DE DEMOCRACIA E JUSTIÇA COMO EQUIDADE NO CONTEXTO BRASILEIRO.
}

\author{
THE RIGHT TO THE CITY AND POPULAR PARTICIPATION : A \\ DISCUSSION FROM DEMOCRACY CONCEPTS AND JUSTICE AS FAIRNESS IN \\ THE BRAZILIAN CONTEXT .
}

\begin{abstract}
${ }^{1}$ Ana Mônica Medeiros Ferreira
\section{RESUMO}

A questão relevante que se propõe é identificar a relação entre as ideias de democracia e justiça como equidade, a partir dos preceitos de liberdade e igualdade para a compreensão do direito à cidade e a efetiva participação popular em nossa realidade brasileira. Para isso, realizamos uma breve incursão no conceito do vocábulo democracia, após esboçamos a contribuição de Robert Dahl para este conceito enquanto ideal a ser perseguido. Por conseguinte, descrevemos a problemática da igualdade e a Justiça como equidade para a concretização dos direitos fundamentais a partir de Jonh Rawls. Analisa-se em seguida a democracia participativa no plano constitucional e a influência dos estudos de Paulo Bonavides, procurando elucidar o verdadeiro significado e sentido da existência da democracia e da participação no interior do ordenamento jurídico. Mais adiante defendemos a participação popular e o direito à cidade como direitos fundamentais. Por fim expomos as conclusões e tecemos algumas reflexões.
\end{abstract}

Palavras-chave: Direito à cidade e participação popular, Democracia, Justiça como equidade

\begin{abstract}
The relevant question that is proposed in this article is to identify the relationship between the ideas of democracy and justice as fairness, from the principles of freedom and equality for understanding the Right to the City and effective popular participation in our Brazilian reality. For this, we made a brief foray into the concept of the word democracy after outline the contribution of Robert Dahl to this concept as an ideal to be pursued. Therefore, we describe the problem of equality and justice as fairness for the realization of fundamental rights from John Rawls. Analyzes then participatory democracy at the constitutional level and the influence of Paulo Bonavides studies, seeking to elucidate the true meaning and sense of the existence of democracy and participation within the legal system. Later we defend the popular participation and the right to the city as fundamental rights. Finally we expose the conclusions and weave some thoughts.
\end{abstract}

Keywords: Right to the city and popular participation, Democracy, Justice as fairness

\footnotetext{
${ }^{1}$ Doutoranda em Ciências Sociais pela Universidade Federal do Rio Grande do Norte, UFRN - RN, (Brasil).

E-mail: anamonicamf@yahoo.com.br
} 


\section{INTRODUÇÃO}

O presente artigo tem por objetivo realizar uma reflexão sobre a relação necessária entre democracia e justiça como equidade na participação popular bem como fomentar o debate acerca da legitimidade da gestão pública e a concretização do direito à cidade e o direito à participação como direitos fundamentais do cidadão.

O estudo partiu das discussões acerca dos aspectos sócio jurídicos do Direito à Cidade na elaboração do Plano Diretor da Cidade de Natal - RN, porém verificou-se que não seria mais tão relevante pesquisar sobre as causas de descumprimento de normas de direito urbanístico, se não fosse possível antes disso estudar a sociedade em que vivemos, a relação de identificação e pertencimento do indivíduo com a sociedade em que vive, quais os mecanismos de participação efetiva de tais indivíduos.

Em outras palavras, constata-se que é preciso entender a fundo as ideias de democracia e justiça, a partir dos preceitos de liberdade e igualdade para a compreensão da nossa realidade.

Acredita-se, portanto, que desconstruir certezas para ir ao encontro de novas certezas fazem parte do percurso do conhecimento. Pesquisar exige discernimento nas escolhas e preservar a sua essência no exercício das opções de como fazer ciência. Nesse trajeto, enfrentar dificuldades, negar falsos problemas e superar equívocos requer coragem, mas exige também cautela.

Em outros tempos começaria o artigo científico pelo texto normativo, provavelmente exaltando a força dos artigos 182 e 183 da Constituição Federal de 1988 e o grande avanço conquistado com o Estatuto da Cidade, e atualmente com o Estatuto da Metrópole. E, provavelmente desenvolveria todo ele a partir da retórica dos instrumentos legais de planejamento e gestão das cidades.

No entanto, o estudo do direito à cidade tomou outras dimensões após ingresso no universo das ciências sociais e, principalmente após os debates de ciência política. Nossas ideias preestabelecidas se transformaram em verdadeiros dilemas; ou seja, acabou por trazer certa insatisfação em relação ao que se estava investigando.

Esse desconforto provocado pela angústia e incerteza foi o que proporcionou o desenvolvimento deste breve estudo. As respostas que se tem sobre o direito a cidade e participação popular não nos parecem satisfatórias. Aliás, nem mesmo as perguntas sobre tais temas nos parecem ser bem formuladas para o enfrentamento do cerne do problema. 
Não importa apenas fomentar a criação de órgãos colegiados de política urbana ou audiências públicas para implementação da gestão democrática prevista pelo Estatuto da Cidade, mas é preciso ir além.

Considerando o eixo temático PODER, CIDADANIA E DESENVOLVIMENTO NO ESTADO DEMOCRÁTICO DE DIREITO, faz-se a reflexão do Direito à cidade a partir das contribuições de alguns autores que desenvolveram modelos teóricos sobre a participação da sociedade na condução dos rumos das cidades.

Fazendo uso da abordagem dialética, esse breve artigo prioriza dois aspectos complementares. O primeiro refere-se ao debate social, que possibilita a ampliação do olhar sobre a temática da efetivação do direito à cidade. O segundo diz respeito ao arcabouço jurídico e aos processos para a garantia de tal direito, incluindo a questão da democracia e a participação popular.

Nesse sentido, a presente análise terá a seguinte estrutura: 1) democracia enquanto vocábulo polissêmico; 2) a contribuição de Robert Dahl para o conceito de democracia enquanto ideal a ser perseguido; 3) a problemática da igualdade e a Justiça como equidade para a concretização dos direitos fundamentais a partir de JonhRawls;4) democracia participativa no plano constitucional e a influência dos estudos de Paulo Bonavides; 5) a participação popular e o direito à cidade como direitos fundamentais; 6); tentativa de conclusão e estímulo a novos debates.

\section{DEMOCRACIA: AS DIFICULDADES DE UM VOCÁBULO POLISSÊMICO}

Tendo em vista que a concretização de direitos fundamentais (partindo da hipótese de se caracterizar o direito a cidade e participação popular enquanto tal) e justiça não se limita a categorias exclusivamente jurídicas, pois ela também traz em si elementos político-filosóficos, não há como se falar de direito à cidade sem passar pela ideia de justiça e tampouco sem se falar de democracia.

Ao começar nossas reflexões é importante entender o que efetivamente é democracia. Pela influência da mídia e do discurso ocidental predominante observamos que o termo democracia possui uma conotação fortemente positiva (assim como o termo cidadania, mas isso deve ser objeto de outro estudo). Conotação esta que pode ser prejudicial para uma leitura desavisada. Ora, até regimes políticos mais autocráticos gostam de ser assim denominados. 
De fato, a enorme diversidade de sistemas políticos autodenominarem-se democráticos contribui para confundir e obscurecer o conceito, tornando-o sinônimo de um consenso universal vazio de conteúdo (CADERMATORI, 2009, p. 17).

A palavra democracia, de origem grega, significa, pela etimologia, demos - povo e kratein - governar. Seu entendimento, porém, não se limita ao etimologismo, pois, ao longo do tempo, diferentes modelos de democracia foram sendo construídos, segundo as conjunturas social e política de cada época.

Apesar de tais conjunturas históricas representarem avanços e retrocessos que a evolução social das nações demonstra, gradativamente, os princípios iniciais do governo democrático foram sendo implantados em duas direções. Por um lado, no sentido da atribuição de direitos políticos que nas cidades antigas eram privilégio de uma pequena parcela da sociedade, ficando a maioria excluída tanto dos direitos políticos quanto dos direitos civis, alcançando-se ao sufrágio universal apenas na metade do século XX. Por outro lado, chegou-se aos princípios democráticos no âmbito de sua aplicação. Foi quando a democracia se deslocou das cidades para os Estados, e a partir da $1^{\text {a }}$ Guerra Mundial, de modo imperfeito, deram-se as primeiras tentativas de expansão da democracia em direção ao sistema internacional (BOBBIO, 2000, p. 420).

O caráter liberal burguês originário da Revolução Francesa e que dá origem à democracia como modelo de gestão do Estado, acabou por restringir a democracia a um sistema político representativo (SOARES, 1997, p. 62).

Em que pese esse sistema ser a expressão do princípio da maioria, elemento sem dúvida importante para o entendimento do real significado do vocábulo, a evolução histórica tem demonstrado a necessidade de complementação, ou, em outras palavras, adequação do mesmo aos dias atuais. Por isso fala-se hoje em democracia participativa enquanto uma nova configuração da democracia conforme veremos a seguir.

Antes disso, para entender o conceito usual de democracia precisamos analisar a relação apontada entre liberalismo e democracia inicialmente a partir de Jean Jacques Rousseau (1983) e Thomas Hobbes (2009).

O ponto de partida para o pensamento democrático moderno é dado pela ideia de governo do povo ou soberania popular. De acordo com Rousseau o poder deixa de ser entendido como vontade divina e passa a ser concebido como um produto da vontade humana, já que, enquanto o poder estiver à procura de sua legitimidade na tradição, direito de conquista ou vontade divina, a democracia será impensável (1983, p. 35). 
A ideia de elo social (CADERMATORI, 2009, p. 60) depois definido como contrato social propriamente foi desenvolvida por pensadores políticos liberais, de Hobbes a Rousseau e ficou conhecido pioneiramente no Bill of Rights de 1689 e acabou sendo consagrado depois pelas revoluções americana e francesa.

O chamado "Contrato Social" inicia um debate político e social que ainda não terminou, legitima o poder e funda a sociedade civil. Elabora os princípios dos direitos fundamentais civis e políticos, cuja autoridade deve ser representada exclusivamente no governo formado através de um pacto social, com cujos princípios deveriam cada cidadão se comprometer individualmente, mediante renúncia de sua liberdade individual em prol de todos os associados que garantirão dignidade, igualdade jurídica e moral e a tão sonhada liberdade civil.

Para Rousseau a única forma de preservar a liberdade natural do homem e ao mesmo tempo garantir a segurança e o bem-estar da vida em sociedade seria através de um contrato social, por meio do qual prevaleceria a soberania da sociedade, a soberania política da vontade coletiva.

Hobbes, em sua obra célebre O Leviatã, mais do que responder às demandas políticas e sociais da Coroa e do povo britânico, suscita diversas questões para a moderna Teoria do Estado: o que leva um povo, ainda que de maneira inexplicável, a celebrar um pacto social? $\mathrm{O}$ Estado é uma virtude, ou destino dos povos? Qual deveria ser o nível de tolerância da sociedade aos desmandos dos governantes? Quando, como e por quem deveriam ser substituídos?

Em que pese os diversos questionamentos e interpretações da obra de Hobbes, podemos dizer que ele acabou por demonstrar que o Estado é necessário, mesmo com suas incongruências.

Pode-se dizer a partir de Hobbes que é dever primordial do Estado garantir a lei e a ordem. Este é o bem público supremo, aquele que resgata o indivíduo da miséria e possibilita a vida em sociedade. Os escritos de Hobbes, embora universalizáveis, identificam-se claramente com os dilemas e conflitos envolvidos na Revolução Inglesa.

A própria legitimidade do Estado depende de sua capacidade de promover os interesses materiais do homem (MICKLETHWAIT, 2015, P. 35).

Tanto Hobbes como Rousseau concordam com o fato de o ser humano ter o direito de preservar a si mesmo, ou seja, sua própria vida, mas discordam na medida em que um acredita em meios soberanos para este fim, enquanto o outro estabelece que medidas democráticas são mais justas e próximas da noção de liberdade, portanto melhores meios para a mesma finalidade. 
Rousseau, então, busca um modelo ideal, em que a felicidade humana possa ser encontrada no dia-a-dia dos cidadãos; a participação política, antes de ser uma questão de segurança e controle social, passa pelo compromisso com a sociedade e, consequentemente, consigo mesmo.

A preocupação de Rousseau com as minorias (inexistentes para o Leviatã) revela não apenas o medo da sucumbência do seu modelo político, mas também a tentativa de se restaurar, ainda que de maneira artificial, o estado (natural) de bondade humana - a ausência de conflitos.

Estudiosos apontam que enquanto Rousseau buscou alcançar a sua paz interior por meio de um pacto entre a sociedade, inspirando-nos a vislumbrar o diálogo entre os diversos segmentos sociais, na busca de um governo que sintetize e harmonize as incontáveis vontades divergentes, Hobbes nos alertou para o dilema insuperável entre os dois monstros bíblicos, reveladores do profundo papel do Estado em nossas vidas - a eterna escolha entre o caos social ou a ordem absoluta- um trágico dilema, ainda a assombrar a humanidade por muitas gerações (PANIZA, 2004).

Enquanto que a democracia não foi discutida por Hobbes, é importante frisar que Rousseau se preocupa profundamente com o tema, mas admite a impossibilidade efetiva da democracia, verdadeira, em função da dificuldade de haver uma assembleia popular permanente ou o governo simultâneo de muitas pessoas investidas de um mesmo cargo.

E, se referindo a democracia em sua forma pura afirma que se tomando o rigor da acepção, jamais existiu e jamais existirá uma democracia verdadeira (1983, p. 84). Na sua visão é contra a ordem natural governar o grande número e ser o menor número governado.

A partir de Rousseau a democracia passa a ser definida sob duas perspectivas: a soberania do povo e os direitos do homem. O homem afirma a sua liberdade colocando-se como cidadão, e é a criação da República que dá maior garantias aos direitos individuais.

É a partir dessa concepção parcial ou talvez incompleta da história que foram sendo construídos diversos os conceitos de democracia participativa e cidadania.

Após Rousseau tivemos importantes contribuições de diversos pensadores para a formulação teórica da democracia, a exemplo de Alexis de Tocqueville e John Stuart Mill sobre a vontade das maiorias nos governos da maioria e o risco de sua potencialidade opressiva, bem como Joseph Schumpeter estudou a luta competitiva dos grupos pelo voto.

Porém não vamos trabalhar com estes autores neste artigo. Por opção metodológica ficamos por ora com as contribuições de Rousseau no seu sentido tradicional de democracia para a seguir desenvolver uma concepção mais atual. 


\section{A CONTRIBUIÇÃO DE ROBERT DAHL PARA O CONCEITO DE DEMOCRACIA EM POLIARQUIA.}

Para trabalhar com a ideia de democracia participativa entendemos ser necessário analisar a obra de Robert Dahl (2005) para uma melhor compreensão do que o autor definiu como democracia ideal e suas diferenças para a democracia real com o escopo de aplicar esses ensinamentos para a realidade brasileira. Robert Dahl é um dos mais conceituados cientistas políticos do pós-guerra.

Destaca-se, essencialmente, por suas reflexões teóricas sobre a democracia contemporânea. Por considerar as democracias existentes em diversas partes do mundo pobres em aproximações do ideal democrático, o autor sugeriu que estas fossem chamadas de poliarquias $(2005$, p. 31$)$.

Pode-se dizer que suas ideias são influenciadas pela perspectiva schumpeteriana, onde a democracia que vigora no mundo moderno pode ser definida como um arcabouço institucional que estabelece regras que definem quem está apto a participar do processo político para escolha dos governantes e quais os meios de disputa do poder político (CADERMATORI, 2009, p. 205).

O modelo schumpeteriano de democracia também é chamado de modelo procedimental ou modelo de democracia formal. Nas palavras de Dahl (2005, p. 31) nenhum grande sistema no mundo real é plenamente democratizado, mas sim representa apenas algum grau de democratização.

Conforme explicitado por Fernando Limongi no prefácio de Poliarquia (DAHL, 2005, p. 11), as categorias de análise básica que fundamentam seu conceito se referem a "participação política" e "competição política". A participação política envolve a inclusão da maioria da população no processo de escolha dos líderes e governantes, enquanto que a dimensão da competição política envolve a disputa pelo poder político que pode levar ao governo.

Na verdade Robert Dahl parte do pressuposto que uma característica chave da democracia é a continua responsividade do governo às preferências de seus cidadãos, considerados como politicamente iguais (2005, p. 25). Ele não leva em consideração outras características e alerta que reserva o termo " democracia" para um sistema político que tenha como uma de suas características, a qualidade de ser inteiramente, ou quase inteiramente, 
responsivo a todos os seus cidadãos. Não é relevante saber se este sistema existe, existiu ou pode existir. Porém, pode-se, seguramente, conceber como um sistema hipotético.

Outro pressuposto que também deve ser levado em consideração diz respeito ao fato de que, para um governo continuar sendo responsivo durante certo tempo aos seus cidadãos, é necessário que todos estes tenham oportunidades plenas de: 1. Formular suas preferências; 2. Expressar suas preferências a seus concidadãos e ao governo através da ação individual e coletiva; 3. Ter suas preferências igualmente consideradas na conduta do governo, ou seja, consideradas sem discriminação decorrente do conteúdo ou da fonte de preferência (2005, p. 26).

Embora o autor revele que essas parecem ser as três condições necessárias à democracia, provavelmente, tais oportunidades vistas de forma isolada, não sejam suficientes.

Para que esses três tipos de oportunidades existam para um grande número de pessoas, como é o caso dos Estados modernos, é preciso que as instituições da sociedade forneçam, pelo menos, as seguintes garantias (2005, p. 27): 1) Liberdade de formar e aderir a organizações. 2) Liberdade de expressão. 3) Direito de voto. 4) Elegibilidade para cargos públicos. 5) Direito de líderes políticos disputarem apoio e votos. 6) Fontes alternativas de informação. 7) Eleições livres e idôneas. 8) Instituições para fazer com que as políticas governamentais dependam de eleições e de outras manifestações de preferências.

$\mathrm{O}$ conceito de poliarquia tem o mérito de permitir que se efetue uma análise mais realística dos regimes democráticos existentes, uma vez que, a partir desse conceito, torna-se possível estabelecer "graus de democratização" e, desse modo, avaliar e comparar os regimes políticos.

A partir dos dois parâmetros de análise mencionados é possível avaliar o grau de democracia de um regime ou sistema político. Quanto maior a inclusão dos cidadãos no processo de escolha dos líderes e governantes (extensão do direito de voto) e quanto mais grupos dentro de uma sociedade competirem pelo poder político, mais democrática é essa sociedade.

Para Robert Dahl, a democratização é formada por pelo menos duas dimensões: contestação pública e direito de participação. E informa que desenvolver um sistema de contestação pública não é necessariamente equivalente à democratização plena. Uma democracia atinge seu grau máximo de desenvolvimento (poliarquia) quando o direito de voto abrange a maioria da população e quando a competição pelo poder político envolve grupos distintos, que têm, no entanto, as mesmas chances de chegar ao governo.

Dentro da sua teoria para estabelecer um modelo procedimental de democracia ele apresenta a seguinte tipologia de sistemas e regimes democráticos (2005, p. 30): 1. Hegemonias fechadas: regimes em que a disputa pelo poder é baixa e a participação política é limitada; 2 . 
Hegemonias inclusivas: regimes em que a disputa pelo poder é baixa, mas a participação política é mais extensa; 3. Oligarquias competitivas: regimes em que a disputa pelo poder é alta, mas a participação política é limitada; e 4. Poliarquias: regimes em que a disputa pelo poder é alta e a participação política é ampla.

Tal construção teórica se faz de grande importância para entender a grande diferença entre o que se diz ser democracia e o que realmente está acontecendo em grande parte do mundo. No nosso campo de pesquisa, particularmente nos interessa estudar a realidade brasileira.

$\mathrm{O}$ autor classifica o Brasil como não-poliarquia no capítulo referente à igualdades e desigualdades, mais precisamente utilizando a questão fundiária como critério de análise (DAHL, 2005, p. 94). Pode-se dizer que as desigualdades extremas no país são desfavoráveis à política competitiva e à poliarquia.

A poliarquia nos remete a um modelo imaginário de democracia procedimental. A inclusão de todo cidadão se desdobra na igualdade do voto, na possibilidade de uma efetiva participação em fóruns de decisão, por intermédio, inclusive, da compreensão do andamento do processo eleitoral e das fórmulas de escolha.

A teoria de Robert Dahl estabelece que para um governo ser classificado como democrático, ele precisa satisfazer pelo menos cinco critérios: "participação efetiva", "igualdade de voto", "aquisição de entendimento esclarecido", "exercício do controle definitivo do planejamento", "inclusão de adultos".

Uma das justificativas apresentadas por Robert Dahl para demonstrar a superioridade e o desejo de democracia, consiste no fato de que tal sistema de governo tende a gerar um grau relativamente elevado de igualdade política entre os seus cidadãos.

Acredita-se que a grande contribuição de Robert Dahl ao debate acerca da democracia é exatamente nesse ponto. Porque na verdade estamos o tempo todo diante de modelos e instituições aparentemente democráticas, mas que se for feita uma análise mais minuciosa não encontraremos os elementos de participação e contestação de forma efetiva.

Definitivamente é o que percebemos no tocante a efetiva gestão democrática das cidades. Não existe uma verdadeira participação do cidadão, tendo em vista o distanciamento real entre o indivíduo e as instâncias de poder. Apesar de formalmente existir esferas institucionalizadas para a democratização dos debates.

Segundo Dahl, a igualdade política é algo inerente à democracia; ela é o alicerce, o fundamento, e somente através dela é possível criar uma associação que satisfaça esses cinco critérios. A ideia de que todos os cidadãos são intrinsecamente iguais passou a ser então uma premissa da própria democracia. 
Tendo em vista tais colocações vários estudiosos se debruçaram em tecer críticas e comentários sobre a aplicabilidade da teoria desenvolvida em poliarquia por Dahl no sistema político brasileiro.

Para Pereira (2015) o governo democrático só se justifica com base no pressuposto de que todos os cidadãos são, de modo geral, igualmente qualificados para participar na tomada das decisões políticas. Ressaltando a competência cívica dos cidadãos adultos, o autor afirmou que não há ninguém tão inequivocamente mais bem preparado do que outros para governar, a quem se possa confiar a autoridade completa e decisiva no governo do Estado.

Para Godoy (2012), do ponto de vista procedimental o modelo democrático se desdobra com pequenas nuances de imprestabilidade no Brasil. Aqui realmente a realidade é outra. No pano de fundo da discussão, a revelação que poderíamos ter uma desigualdade econômica que pautaria uma absoluta desigualdade política. No combate a essa ameaça é que surgem mecanismos de controle de governo e de burocratas.

Tem-se que a grande problemática apresentada é exatamente como lidar com asdesigualdades. E, principalmente como construir uma democracia a partir de tais parâmetros. Pela análise da obra de Robert Dahl percebe-se que um governo democrático (ou o mais próximo a esse ideal - poliarquia) constitui apenas um componente da noção normativa que se entende por sociedade democrática.

\section{IGUALDADE E A JUSTIÇA COMO EQUIDADE PARA A CONCRETIZAÇÃO DOS DIREITOS FUNDAMENTAIS A PARTIR DE JONH RAWLS.}

O pensamento filosófico e político de John Rawls, envolve temáticas de justiça, igualdade, liberdade e tolerância mútua. Sua obra Uma Teoria da Justiça se faz essencial para entender a temática da democracia e do direito a participação enquanto direito fundamental.

Logo no prefácio da edição revista John Rawls (2008) adverte que considera as ideias e objetivos da concepção de justiça como equidade os mesmos da concepção filosófica da democracia constitucional. Ele espera que o seu conceito pareça razoável e útil, mesmo que não seja totalmente convincente, para uma vasta gama de opiniões políticas ponderadas e, assim, expresse uma parte essencial do núcleo universal da tradição democrática. Sua ideia é fornecer uma alternativa ao utilitarismo que na sua opinião não oferece uma teoria satisfatória dos direitos e liberdades fundamentais dos cidadãos como pessoas livres e iguais (requisito importante para as instituições democráticas). 
O autor propõe uma nova concepção do tradicional contrato social, tal como concebida por pensadores como John Locke, Jean Jacques Rousseau e Immanuel Kant.

A partir de uma situação inicial que contém certas restrições procedimentais aos argumentos apresentados, o escopo é levar a um consenso original no tocante aos princípios de justiça (RAWLS, 2008, p. 313).

Rawls (2008, p. 14). para construir a sua teoria, parte de uma "Posição Original", cujo raciocínio se opera da seguinte forma: 1 . Imagine que estamos reunidos com a finalidade de criar um novo contrato social; 2. Imagine que temos que definir os princípios que fundamentaram os pilares do novo contrato social; 3. Imagine quais princípios seriam os pilares deste contrato social.

$\mathrm{O}$ autor sugere uma interpretação na qual as partes da posição original caracterizariam pessoas autônomas, que intentam dar expressão a sua natureza enquanto seres racionais livres e iguais, e os princípios de justiça que se assemelhariam aos imperativos categóricos de Kant, por serem frutos de tal deliberação e por sua necessidade de aceitação universal (2008, p. 311-320).

Entendendo a sociedade complexa e os interesses múltiplos dos indivíduos, ideia proposta é excluir o conhecimento das contingências que geram discórdias entre os homens e que esse instrumento permitissem a ação dos homens livre de preconceitos e de maneira natural (2008, p. 22-23).

A ideia de uma posição original é configurar um procedimento equitativo, de modo que quaisquer princípios acordados nessa posição sejam justos, baseados na ideia do imperativo categórico kantiano. Devemos, de algum modo, anular as consequências de contingências específicas que geram discórdia entre os homens, tentando-os a explorar as circunstâncias sociais em benefício próprio. Para fazê-lo, presumo que as partes se situam por trás de um véu de ignorância. Elas desconhecem as consequências que as diversas alternativas podem ter sobre a situação de cada qual e são obrigadas a avaliar os princípios apenas com base em ponderações gerais (2008, p. 165-166).

Neste cenário imaginário, os princípios escolhidos para reger uma espécie de novo pacto social, isto é, os princípios fundamentais da sociedade de acordo com a teoria apresentada regerão a sua estrutura básica, que compreende as principais instituições da sociedade e da conjuntura por ela criada.

Rawls (2008, p. 73) estabelece dois princípios de justiça para instituições. 1. Cada pessoa deve ter um direito igual ao mais abrangente sistema total de liberdades básicas iguais que seja compatível com um sistema de liberdade para todos. 2. As desigualdades econômicas e 
sociais devem ser dispostas de modo a que tanto: (a) se estabeleçam para o máximo benefício possível dos menos favorecidos que seja compatível com as restrições do princípio da poupança justa, como (b) estejam vinculadas a cargos e posições abertos a todos em condições de igualdade equitativa de oportunidades.

O primeiro princípio estabelece as liberdades fundamentais enquanto o segundo princípio de justiça deve ser interpretado democraticamente através da combinação do princípio da igualdade equitativa de oportunidade e o princípio da diferença (2008, p. 91).

O princípio da igualdade equitativa de oportunidade determina que toda e qualquer pessoa possa disputar em condições de igualdade com os seus pares a cargos, esta configuração (acessibilidade a cargos e carreiras) é importante para distribuir os benefícios, os cargos e autoridades em uma sociedade.

Já o princípio da diferença supera a ideia clássica de justiça distributiva, porquanto o que cada um obtém só é justo se os benefícios ou posições também forem acessíveis aos demais.

Ao desenvolver o princípio da diferença e sua tendência à igualdade, o autor revela que ninguém merece sua maior capacidade natural nem um ponto de partida mais favorável na sociedade. Porém é claro que isso não é motivo para ignorar, muito menos eliminar, essas diferenças. Pelo contrário, pode-se organizar a estrutura básica de forma que essas contingências funcionem para o bem dos menos afortunados. Assim somos levados ao princípio da diferença se desejarmos configurar o sistema social de modo que ninguém ganhe ou perca devido a seu lugar arbitrário na distribuição de dotes ou de sua posição original na sociedade sem dar ou receber benefícios compensatórios em troca (2008, p. 121-122).

A distribuição natural não é justa nem injusta; nem é injusto que se nasça em determinada posição social. Isso são meros fatos naturais. Justo ou injusto é o modo como as instituições lidam com esses fatos.

Para o autor é a estrutura básica da sociedade favorece alguns pontos de partida em detrimento de outros. Ou seja, as instituições que compõem a estrutura básica da sociedade, tais como igrejas, associações, universidades, etc. favorecem mais a uns do que outros provocando desigualdades e afetando as possibilidades de vida de cada sujeito. São essas desigualdades que os princípios de justiça devem regular.

Para o nosso estudo importa frisar que as desigualdades sociais sempre existirão nas cidades, não apenas no Brasil, mas em todo o mundo. O que na verdade deve ser aperfeiçoado é como são planejadas e executadas as políticas públicas pelas instituições, considerando as diversidades sociais e espaciais. Verifica-se que é urgente pensar em um novo padrão de 
intervenção nas cidades com o intuito de mitigar as desigualdades e desacelerar a apropriação privada do desenvolvimento da cidade.

Para Godoy (2010) a teoria da justiça de Rawls se funda em princípios previamente justificados, fundada na moral e servirão de fundamento para que a razão pública desempenhe o papel de articular as pretensões normativas de justiça e o contexto social. A teoria da justiça de Rawls, aliada ao seu conceito razão pública, expressa um ideal de cidadania democrática de tal forma que sua concepção de justiça esteja intimamente ligada a teoria da democracia deliberativa.

Alguns autores contemporâneos a exemplo do jurista Ronald Dworkin e do economista Amartya Sen apontaram falhas na teoria de Rawls, mas ambas as críticas não retiram a grande importância do autor para o estudo dos direitos fundamentais e da democracia.

Por isso a teoria da justiça como equidade significa, antes de mais nada, amparar os desvalidos, corrigindo as desigualdades sociais. Ela vai além do cumprimento da lei, sendo filosoficamente coerente com o real sentido da democracia.

Entendendo que não podemos importar modelos epistemológicos para a sua aplicação na realidade brasileira sem a devida reflexão, após analisar as teorias norte americanas

de Robert Dahl e John Rawls cumpre trazer para o debate as ideias de um autor brasileiro acerca da democracia e investigar qual o real papel da democracia no contexto da efetivação de direitos no Brasil, considerando suas peculiaridades sociais, econômicas e culturais, bem como levando em conta a estruturação das instituições pátrias.

\section{DEMOCRACIA PARTICIPATIVA NO PLANO CONSTITUCIONAL E A INFLUÊNCIA DOS ESTUDOS DE PAULO BONAVIDES.}

Partimos da hipótese que todo o sistema constitucional se estrutura a partir do princípio democrático. Esse princípio acolhe diversos postulados da teoria democrática representativa, tais como órgãos representativos, eleições periódicas, pluralismo partidário, separação de poderes. Além disso representa o reconhecimento constitucional da participação dos cidadãos.

Cumpre aqui tecer algumas considerações acerca dos princípios constitucionais para entender a topologia constitucional do princípio democrático na Constituição Federal de 1988.

A classificação dos princípios constitucionais não é homogênea uma vez que existe uma enorme gama dessas normas, as quais contêm diversas características, o que dificulta uma 
categórica classificação. Tais classificações orientam-se de modo geral pelo critério de generalidade e positividade, partindo dos princípios gerais do Direito, depois os que se referem a uma determinada concepção político social, e finalmente os mais específicos, dotados de uma maior precisão.

Canotilho (2003, p. 1165-1177) divide os princípios constitucionais em quatro categorias: princípios jurídicos fundamentais, que antes mesmo de serem apreciados como princípios específicos do Direito Constitucional são princípios gerais do direito, a exemplo do princípio da publicidade e da proporcionalidade; princípios políticos constitucionalmente conformadores, que são princípios constitucionais que explicitam as valorações políticas fundamentais, nucleares, do legislador constituinte, a exemplo do princípio democrático e do princípio republicano; princípios constitucionais impositivos, que são os que, sobretudo no âmbito da constituição dirigente impõem aos órgãos do estado a realização de fins e execução de tarefas, a exemplo da redução das desigualdades regionais; e, os princípios-garantia, que são os princípios de maior densidade normativa e menor grau de vagueza, permitindo o estabelecimento direto de garantias para os cidadãos, a exemplo da legalidade estrita em matéria criminal.

José Afonso da Silva (2003, p. 92-95), por sua vez, divide os princípios da Constituição brasileira basicamente em duas categorias: a dos princípios político constitucionais e a dos princípios jurídico-constitucionais. Os princípios político constitucionais são as decisões fundamentais do legislador constituinte sobre a existência política da nação, concretizadas em normas conformadoras do sistema constitucional positivo, das quais decorrem as normas reguladoras das relações da vida social.

Encontram-se materializados nos artigos $1^{\circ}$ ao $4^{\circ}$ da Constituição Federal de 1988 e dizem respeito à existência, forma, estrutura e tipo de Estado; à forma de governo e à organização dos poderes; à organização da sociedade; ao regime político; à prestação positiva do Estado; e à comunidade internacional. Já os princípios jurídicos constitucionais compreendem aqueles princípios constitucionais gerais que informam a ordem jurídica nacional, muitas vezes derivados dos princípios fundamentais, a exemplo do princípio da supremacia da Constituição, da legalidade, os chamados princípios garantias que figuram no art. $5^{\circ}$ da Carta Magna. 
Independentemente da classificação a ser seguida tem-se que o princípio democrático é princípio material estruturante do ordenamento pátrio estando consubstanciado no artigo $1^{\circ}$ da Constituição Federal de 1988. Ademais configura nosso diploma a cidadania enquanto fundamento e elemento essencial do Estado Democrático de Direito1.

A ideia de Estado Democrático de Direito está associada, necessariamente, à existência de uma Sociedade Democrática de Direito, o que de uma certa forma resgata a tese de que o conteúdo do conceito de democracia aqui se assenta na soberania popular (poder emanado do povo) e na participação popular, tanto na sua forma direta como indireta, configurando o que podemos chamar de princípio participativo, ou, em outras palavras (SOARES, 1997, p. 34): democratizar a democracia através da participação significa em termos gerais, intensificar a optimização das participações dos homens no processo de decisão.

Feito esse breve registro sobre a classificação dos princípios cumpre trazer a importante contribuição do Professor Doutor Paulo Bonavides (2001) nos seus textos publicados na Teoria Constitucional da Democracia Participativa (por um Direito Constitucional de luta e resistência; por uma Nova Hermenêutica; por uma repolitização da legitimidade).

Sua análise no campo jurídico e político tem fundamental importância pois ele procura redimensionar a democracia brasileira, adotando uma perspectiva constitucional definitiva. Propõe uma luta e a resistência pela democracia e pelo fortalecimento da Constituição. Democracia, para Bonavides (2001, p. 57-58) é processo de participação dos governados na formação da vontade governativa; participação que se alarga e dilata na direção certa de um fim, todavia inatingível: a identidade de governantes e governados.

Pode-se dizer que democracia é processo, é continuidade, é a busca por um ideal. Nesse sentido observamos que a sua concepção se relaciona com os outros autores analisados anteriormente. É como se a democracia fosse ao mesmo tempo reagente e catalizador, pois ela é própria e o seu desenvolvimento é requisito de sua manutenção.

\footnotetext{
1Art. $1^{\circ}$. A República Federativa do Brasil, formada pela união indissolúvel dos Estados e Municípios e do Distrito Federal, constitui-se em Estado Democrático de Direito e tem como fundamentos: I - a soberania;

II - a cidadania; III - a dignidade da pessoa humana; IV - os valores sociais do trabalho e da livre iniciativa;

V - o pluralismo político. Parágrafo único: Todo o poder emana do povo, que o exerce por meio de representantes eleitos ou diretamente, nos termos desta Constituição.
} 
Outra ideia muito importante trazida por Paulo Bonavides (2001, p. 59) é a participação popular. Explica que a participação deu princípio à democracia na categoria tradicional e clássica dos chamados direitos fundamentais da primeira geração. Percorreu, a seguir, lenta evolução pelo caminho da subjetividade. Direito da primeira geração, a democracia se concretizava aí apenas no domínio individual e na dimensão subjetiva. Seu titular, por conseguinte, é o indivíduo, o cidadão, o sujeito, enquanto membro ou partícipe de um processo onde a democracia não alcançava ainda a vertente principal da positividade, que aufere depois nas Constituições, quando se reconhece que os princípios são mais direito do que ideia ou norma programática. Do ponto de vista qualitativo, ao assumir, porém, a dimensão objetiva, o direito fundamental à democracia varia de titularidade axiológica e se traslada do cidadão para o gênero humano.

Para Bonavides, o atual "neoliberalismo", com o apoio dos beneficiários da democracia representativa implantada e incrustada em seus países, e que exclui o interesse próprio da população, busca com todo empenho legitimar uma globalização injusta imposta de forma desfigurada e degenerativa aos povos da América Latina². Analisa a 2 Neoliberalismo é utilizado pelo autor enquanto uma crítica ao sistema econômico vigente e não quanto ao liberalismo político clássico. Bonavides entende que são nefastas muitas questões que surgem com a globalização de mercados, como a defesa de uma maior desregulamentação econômica, com privatizações de empresas estatais e afrouxamento das garantias dos trabalhadores, dentre outras ações que garantiriam maior liberdade à iniciativa privada. O que desejamos destacar é a diferença entre o que significou o termo questão historicamente e diz que houve uma total usurpação da titularidade da soberania do poder do povo nas democracias, a partir da instituição do estado democrático burguês em fins do século XVIII até o estado constitucional moderno dos dias atuais.

Bonavides adverte para a falência do modelo de democracia representativa, na construção de uma sociedade mais justa e igualitária. Para ele, a essência de um figurino de constitucionalidade que pode ser o mais democrático, o mais aberto, o mais legítimo de organização emancipatória da sociedade brasileira, afigura-se ser o da democracia participativa constitucional (2001, p. 25).

\footnotetext{
2 Neoliberalismo é utilizado pelo autor enquanto uma crítica ao sistema econômico vigente e não quanto ao liberalismo político clássico. Bonavides entende que são nefastas muitas questões que surgem com a globalização de mercados, como a defesa de uma maior desregulamentação econômica, com privatizações de empresas estatais e afrouxamento das garantias dos trabalhadores, dentre outras ações que garantiriam maior liberdade à iniciativa privada. O que desejamos destacar é a diferença entre o que significou o termo "liberalismo", no seu início com as obras de Locke e Montesquieu, quando se referia às garantias de liberdade; e hoje, quando se acha esmagado pela pressão econômica, aparecendo apenas como uma escravização decorrente das chamadas "leis do mercado".
} 
Acredita-se que a grande relevância de sua obra foi mostrar a necessidade da participação social para a efetivação da democratização do Estado brasileiro, rompendo com a visão tradicional política, na qual o cidadão encerra sua atividade no ato de votar.

Bonavides resgata o cidadão da condição de coadjuvante e o insere como protagonista do processo político.

Nesse diapasão pode-se inferir que o Estatuto da Cidade foi elaborado inspirado nas ideias propostas pelo jurista Paulo Bonavides ao estabelecer que a gestão democrática se constitui como instrumento para alcançar o pleno desenvolvimento das funções sociais da cidade e da propriedade urbana.

Cumpre agora identificar a participação popular e o direito à cidade enquanto direitos fundamentais para melhor visualização da conexão entre democracia e justiça como equidade na realização de políticas públicas para a cidade.

\section{A PARTICIPAÇÃO POPULAR E O DIREITO À CIDADE COM OS DIREITOS FUNDAMENTAIS}

O conceito moderno de democracia, independente da linha teórica utilizada tem por base o postulado da soberania popular enquanto o poder emanado do povo, sendo o pilar central do Estado Democrático de Direito. Nesse sentido a constituição de 1988 acabou por contemplar no parágrafo único do seu artigo primeiro (Todo o poder emana do povo, que o exerce por meio de representantes eleitos ou diretamente, nos termos desta Constituição) tanto a democracia representativa ou indireta quanto a democracia participativa, a partir da expressão diretamente.

Percebe-se a presença da democracia representativa e a democracia participativa de forma complementar e não excludente.

Entretanto, apenas tal referência à participação no texto constitucional, embora apontem para a importância da participação, não trariam um quadro concreto capaz de alçar a participação popular à categoria de direito fundamental, ao menos quando se observa unicamente o ordenamento positivo brasileiro.

A participação popular na Administração não consta, explicitamente, do rol de direitos e garantias fundamentais previstos na Constituição que foi aprovada em 1988 e alterada por, até então, 88 emendas, afora as seis revisionais. Ou seja, não se encontrará no corpo dela previsão expressa assegurando a participação popular na Administração como um direito fundamental.

Porém, isto não significa, entretanto, que tal direito não esteja contemplado pela sistemática constitucional. De fato, a abertura do sistema constitucional aos direitos 
fundamentais, e a interpretação do $\S 2^{\circ}$ do artigo $5^{\circ}$ da Constituição, não deixa dúvidas quanto à existência de direitos fundamentais implícitos. Implicitamente, então, a participação se configura em direito fundamental.

Tal posicionamento é decorrência lógica da soberania do popular. Sendo o povo brasileiro, em essência, o titular do poder no Estado brasileiro, pertenceria aos cidadãos, mesmo que com limitações - tais como as inerentes ao sistema representativo, ou às regras condicionantes para a participação direta - o direito a participar na condução dos assuntos estatais. Ora, se a função administrativa figura entre as funções estatais, logicamente também haveria um direito à participação nesta, pelo menos em abstrato.

Ademais é importante situar a participação popular como um direito e não uma concessão do poder público. Deve ser incorporado ao aprimoramento da relação governo e sociedade, objetivando construir a cogestão do Estado, com o escopo de atingir os objetivos fundamentais da nação dispostos no artigo $3^{\circ}$ da Constituição³.

Já no tocante ao direito à cidade, temos mais claramente a definição de direito fundamental, uma vez que os artigos 182 e 183 da Constituição Federal que compõem o capítulo da Política Urbana, alteraram o status jurídico das cidades, reconheceram a plena urbanização do Brasil e adotaram organização socioeconômica e político-territorial diversas dos institutos civilistas até então existentes 4.

Mais de dez anos depois foi promulgada lei regulamentadora desses dispositivos constitucionais. Este marco fundamental é o Estatuto da Cidade, Lei 10257/01. E este ano de foi promulgada a Lei 13089/15 que estabelece diretrizes gerais para o planejamento, a gestão e a execução das funções públicas de interesse comum em regiões metropolitanas e em aglomerações urbanas instituídas pelos Estados.

\footnotetext{
3 Art. $3^{\circ}$ Constituem objetivos fundamentais da República Federativa do Brasil: I - construir uma sociedade livre, justa e solidária; II - garantir o desenvolvimento nacional; III - erradicar a pobreza e a marginalização e reduzir as desigualdades sociais e regionais; IV - promover o bem de todos, sem preconceitos de origem, raça, sexo, cor, idade e quaisquer outras formas de discriminação.

4 Art. 182. A política de desenvolvimento urbano, executada pelo Poder Público municipal, conforme diretrizes gerais fixadas em lei, tem por objetivo ordenar o pleno desenvolvimento das funções sociais da cidade e garantir o bem-estar de seus habitantes. $§ 1^{\circ} \mathrm{O}$ plano diretor, aprovado pela Câmara Municipal, obrigatório para cidades com mais de vinte mil habitantes, é o instrumento básico da política de desenvolvimento e de expansão urbana. $\S 2^{\circ}$ A propriedade urbana cumpre sua função social quando atende às exigências fundamentais de ordenação da cidade expressas no plano diretor. $\S 3^{\circ}$ As desapropriações de imóveis urbanos serão feitas com prévia e justa indenização em dinheiro. $\S 4^{\circ}$ É facultado ao Poder Público municipal, mediante lei específica para área incluída no plano diretor, exigir, nos termos da lei federal, do proprietário do solo urbano não edificado, subutilizado ou não utilizado, que promova seu adequado aproveitamento, sob pena, sucessivamente, de: I - parcelamento ou edificação compulsórios; II - imposto sobre a propriedade predial e territorial urbana progressivo no tempo; III - desapropriação com pagamento mediante títulos da dívida pública de emissão previamente aprovada pelo Senado Federal, com prazo de resgate de até dez anos, em parcelas anuais, iguais e sucessivas, assegurados o valor real da indenização e os juros legais. Art. 183. Aquele que possuir como sua área urbana de até duzentos e cinquenta metros quadrados, por cinco anos, ininterruptamente e sem oposição, utilizando-a para sua moradia ou de sua família, adquirir-lhe-á o domínio, desde que não seja proprietário de outro imóvel urbano ou rural. $\S 1^{\circ} \mathrm{O}$ título de domínio e aconcessão de uso serão conferidos ao homem ou à mulher, ou a ambos, independentemente do estado civil. $\S 2^{\circ}$ Esse direito não será reconhecido ao mesmo possuidor mais de uma vez. $\S 3^{\circ}$ Os imóveis públicos não serão adquiridos por usucapião.
} 
É importante ressaltar aqui a relação original entre as palavras cidade e cidadão, que surge muito antes dos dispositivos legais instituídos. De acordo com a etimologia das palavras, ambas derivam de civis. Dessa forma, cidade (civitas) é uma comunidade política cujos partícipes, os cidadãos, se organizam e governam; e cidadão é o indivíduo que goza do direito de cidade, ou seja, é o sujeito que pertence a determinado lugar.

No entanto, o problema do Brasil não é a falta de lei ou regulamentação. A negação do direito à cidade se expressa na irregularidade fundiária, no déficit habitacional e na habitação inadequada, na precariedade e deficiência do saneamento ambiental, na baixa mobilidade e qualidade do transporte coletivo e na degradação ambiental.

Paralelamente, as camadas mais ricas continuam acumulando cada vez mais e podem usufruir um padrão de consumo de luxo exagerado.

Nas palavras da professora Ermínia Maricato (1996), é exatamente no contexto dessa contradição expressa na segregação urbana que explode a violência e cresce o poder do crime organizado na cidade. Os paradigmas hegemônicos do urbanismo e do planejamento urbano têm revelado seus limites e não estão conseguindo dar respostas aos problemas contemporâneos das grandes cidades.

De acordo com nossa Constituição Federal a política urbana deve ser, necessariamente, produto resultante da participação popular. Mas a questão não é apenas jurídica. O Brasil não tem tradição em efetivos instrumentos de participação e tampouco no compartilhamento na solução de problemas da esfera pública.

Observa-se que não é suficiente o comando constitucional de garantia da participação popular e o dever do Estado na sua efetivação, importa agregar um outro elemento: o compromisso político e programático do governo, que comanda as diferentes parcelas do Estado.

Essa ideia é a partir da teoria de Habermas (2001, p. 71), acredita-se que a lista dos problemas que se impõe atualmente deve ser pensada em uma agenda política capaz de dar confiança ao indivíduo em participar das ações do estado e provocar a transformação da sociedade. O diagnóstico dos conflitos sociais transforma-se em uma série de desafios políticos apenas quando as instituições igualitárias do direito racional se conectam a uma importante premissa, a saber, à admissão de que os cidadãos reunidos de uma coletividade democrática podem configurar o seu âmbito social e podem desenvolver a ação necessária para a intervenção.

Verifica-se muitas vezes que a Administração não se mostra favorável à participação, mesmo em pastas que historicamente adotam modelos em tese "democráticos".

Tome-se, por exemplo, uma audiência pública. Nesta os cidadãos podem expor pessoalmente suas ideias, dialogando com um gestor público eleito democraticamente ou com os 
responsáveis pela condução das políticas públicas indicados por ele ou sob seu controle hierárquico. Concretamente, o que se percebe é que não existe uma complementaridade entre as formas de participar. Não existe um diálogo para a construção de propostas e projetos concretos. O que se tem são espaços onde o gestor publica ideias previamente construídas sem a participação popular e as audiências servem apenas para dar uma certa aparência de legitimidade popular.

A partir do momento que se considera que a participação, enquanto direito fundamental, seria calcada na soberania popular já se sublinha um aspecto visivelmente político da participação administrativa. Dessa forma a participação deveria ser efetiva, com real possibilidade de intervenção nas decisões do poder público e nos rumos da sociedade em que o cidadão está inserido.

Para Habermas (2001, p. 77) o conceito jurídico da auto legislação deve ganhar uma dimensão política e ser ampliado nos termos do conceito de uma sociedade que atua sobre si mesma de modo democrático. Apenas assim, pode-se ler nas Constituições existentes o projeto de efetivação de uma sociedade justa e bem ordenada.

Assim, os contornos deste direito fundamental implícito, poderiam ser mais adequadamente desvendados pensando-o como um direito político.

Exemplificando o direito a participação popular e o direito à cidade no contexto local se faz necessário lembrar da total falta de compromisso do poder público com a realização dos conselhos previstos pelo Estatuto da Cidade. Com cinco anos de atraso, a Revisão do Plano Diretor de Natal deverá ocorrer apenas em março de 2016. Até lá, alguns estudos complementares aos já realizados pela Secretaria Municipal de Meio Ambiente e Urbanismo (Semurb), deverão ser feitos por consultorias contratadas pelo órgão 5. Mas a população, maior interessada na aprovação da lei e que deveria ter sido consultada, não está inserida no contexto das discussões apresentadas.

5 As principais mudanças em relação à polêmica versão de 2007, aprovada sob o pagamento de propina a alguns vereadores que compunham a Legislatura Municipal à época, deverão ser discutidas publicamente a partir do segundo semestre deste ano de 2015. 
David Harvey (2015) coloca que nesse ponto atual da história, a luta pela cidade tem de ser uma luta global, predominantemente contra o capital financeiro, pois essa é a escala em que ocorrem hoje os processos de urbanização. Sem dúvida, a tarefa política de organizar um tal confronto é difícil, se não desanimadora. Mas as oportunidades são múltiplas, pois, como mostra esta breve história, as crises eclodem repetidas vezes em torno da urbanização e a metrópole é hoje o ponto de confronto a respeito da acumulação de capital pela desapropriação dos menos favorecidos e do tipo de desenvolvimento que procura colonizar espaços para os ricos. Um passo para a unificação dessas lutas é adotar o direito à cidade, como slogan e como ideal político, precisamente porque ele levanta a questão de quem comanda a relação entre a urbanização e o sistema econômico. A democratização desse direito e a construção de um amplo movimento social para fazer valer a sua vontade são imperativas para que os despossuídos possam retomar o controle que por tanto tempo lhes foi negado e instituir novas formas de urbanização. Lefebvre estava certo ao insistir em que a revolução tem de ser urbana, no sentido mais amplo do termo; do contrário, não será nada.

Entendemos que para superar certas forças ocultas, ou pelo menos assim se apresentam, como o capital financeiro, oligarquias políticas e especulação imobiliária, deve-se repactuar a relação de Estado com a sociedade, como forma de evitar a mitigação dos espaços decisórios e de participação popular, como meios de frear o autoritarismo legislativo e assim tentar salvar o que nos resta de uma "democracia" (se é que é possível utilizar esse termo após nosso estudo teórico e o choque com a realidade pátria).

\section{CONSIDERAÇÕES FINAIS}

Não é nossa pretensão realizar conclusões fechadas acerca da temática. Muito pelo contrário, objetivo dessas reflexões foram fomentar o debate da democracia na realidade brasileira, mais especificamente verificar a dificuldade de uma verdadeira participação popular e efetivo exercício do direito à cidade.

No primeiro capítulo tratamos da democracia a partir das ideias clássicas de Rousseau para ser possível construir as fundações do conceito adotado até os dias atuais.

Podemos concluir que apesar de ser um vocábulo polissêmico, a democracia está intrinsecamente relacionada a um contrato social e pretende consagrar a soberania popular. 
No segundo capítulo analisamos a contribuição de Robert Dahl para o conceito de democracia enquanto ideal a ser perseguido e acreditamos ter sido muito útil a criação da palavra poliarquia para entender definitivamente que democracia é um ideal ou pelo menos um processo em eterna construção.

No terceiro capítulo enfrentamos a problemática da igualdade e a Justiça como equidade para a concretização dos direitos fundamentais a partir de JonhRawls.

Percebemos que o autor propõe uma nova concepção do tradicional contrato social. Essa teoria da justiça como equidade, aliada ao seu conceito razão pública, expressa um ideal de cidadania democrática de tal forma que sua concepção de justiça esteja intimamente ligada a teoria da democracia.

No quarto capítulo traçamos breves linhas acerca da democracia participativa no plano constitucional e a influência dos estudos de Paulo Bonavides. Partimos da compreensão dos princípios constitucionais para entender a força normativa do princípio democrático e a necessidade de um novo conceito de democracia para além da esfera institucional.

No quinto capítulo defendemos a participação popular e o direito à cidade como direitos fundamentais. Porém em que pese a existência de um arcabouço normativo, verifica-se na prática a total negação de tais direitos.

É importante notar que a desigualdade sempre irá existir, seja no seu sentido econômico, cultural ou social. O problema é se entender verdadeiramente o valor da equidade e da inclusão, valores já discutidos neste artigo. E, principalmente, a partir disso discutir e planejar como o Estado pode eleger suas prioridades para dar sentido a uma verdadeira participação social. Porque para superar os problemas da cidade acreditamos que somente a mobilização da comunidade pode transformar a nossa realidade.

Percebemos que um importante desafio para se atingir o objetivo da soberania popular é o reconhecimento dos direitos de participação popular e do direito à cidade por parte da população. É difícil reivindicar aquilo que não se conhece. Defendemos uma participação coletiva e consciente. E não uma massa de manobra para políticos.

A pesquisa sobre democracia realizada neste artigo teve como objetivo analisar a relação de identificação e pertencimento do indivíduo com a sociedade em que vive, para se verificar na prática quais os reais mecanismos de participação efetiva de tais indivíduos. Em outras palavras, reforçamos que é preciso entender a fundo as ideias de democracia e justiça, a partir dos preceitos de liberdade e igualdade para a compreensão da nossa realidade e de seus instrumentos normativos. 
Como tentamos argumentar, a estrutura legal trazida pelo Estatuto da Cidade estabelecendo a participação efetiva da população na gestão, indica o potencial desse espaço em se constituir em esfera pública de concertação entre os diferentes atores e seus respectivos interesses em torno de políticas públicas pactuadas socialmente.

Percebe-se que a cidade vivida é o resultado da dinâmica política e das diferentes formas conforme os agentes sociais exercerão o poder, em dadas condições históricas.

Em outras palavras, como as políticas públicas incidem sobre a cidade, dada a realidade sócio econômica e cultural de determinado território.

Mesmo que não se discuta integralmente a ideia do direito a cidade sustentável, a participação popular poderia possibilitar a proposição de uma nova política de desenvolvimento urbano e de políticas de novo tipo nas áreas de habitação, de saneamento ambiental, de mobilidade e transporte, e de planejamento territorial urbano.

Com base em tudo que foi exposto a única conclusão que podemos chegar é que o diálogo acerca da democracia e dos direitos de participação é essencial para minimizar os efeitos da desigualdade e dominação nas cidades. Porém os caminhos para a efetiva democracia são diversos e merecem estudos mais aprofundados. Espera-se assim que este seja um primeiro passo para o fortalecimento de estratégias na perspectiva da promoção do direito à cidade.

\section{REFERÊNCIAS}

BOBBIO, Norberto. Teoria geral da política: a filosofia política e a lição dos clássicos. Rio de Janeiro: Campus, 2000.

BONAVIDES, Paulo. Teoria Constitucional da Democracia Participativa: Por um Direito Constitucional de luta e resistência. Por uma Nova Hermenêutica. Por uma repolitização da legitimidade. São Paulo: Malheiros Editores, 2001.

CADERMATORI, Daniela Mesquita Leutchuk de. O diálogo democrático. Curitiba: Juruá, 2009.

CANOTILHO, José Joaquim Gomes. Direito Constitucional e Teoria da Constituição. 7. ed. Coimbra: Almedina, 2003.

DAHL, Robert A. Poliarquia: participação e oposição. São Paulo: EDUSP, 2005. DWORKIN, Ronald. Uma Questão de Princípio. Trad. Luis Carlos Borges. São Paulo: Martins Fontes, 2005.

GODOY, Arnaldo Sampaio de Moraes. O americano Robert Dahl e o conceito de poliarquia. Revista Consultor Jurídico, 18 de novembro de 2012. Disponível em: $<$ http://www.conjur.com.br/2012-nov-18/embargos-culturais-ameircano-robert-dahlconceitopoliarquia\#author> Acesso em: 03 de jun de 2015. 
GODOY, Miguel Gualano de. Justiça, democracia e direitos fundamentais: o liberalismo igualitário de John Rawls, o procedimentalismo de Jürgen Habermas e a proposta de Carlos Santiago Nino. Trabalho publicado nos Anais do XIX Encontro Nacional do CONPEDI realizado em Fortaleza - CE nos dias 09, 10, 11 e 12 de Junho de 2010.

Disponível em: < http://www.conpedi.org.br/manaus/arquivos/anais/fortaleza/3466.pdf $>$. Acesso em 30 de mai de 2015.

HABERMAS, Jurgen. A constelação pós-nacional: ensaios políticos. São Paulo: LitteraMundi, 2001.

HARVEY, David. O direito à cidade. Revista Piauí. Edição 82. Disponível em: $<$ http://revistapiaui.estadao.com.br/edicao-82/tribuna-livre-da-luta-de-classes/o-direitoacidade>. Acesso em 01 de abr de 2015.

HOBBES, Thomas. Leviatã. São Paulo: Martin Claret, 2009.

MARICATO, Ermínia. Metrópole na Periferia do Capitalismo: ilegalidade, desigualdade e violência. São Paulo: Editora Hucitec, 1996.

MICKLETHWAIT, John. A quarta revolução: a corrida global para reinventar o Estado. São Paulo: Portfolio-Penguin, 2015.

PANIZA, Alexandre de Lima. Democracia e contratualismo nas concepções de Hobbes e Rousseau - uma abordagem histórica. Revista Brasileira de Direito Constitucional. N. 3, jan./jun. - 2004. Disponível em: <http://esdc.com.br/seer/index.php/rbdc/article/view/70 >. Acesso em: 02 de jun de 2015.

PEREIRA, AntonioKevan Brandão. Teoria democrática contemporânea: o conceito de Poliarquia na obra de Robert Dahl. 38 ENCONTRO ANUAL DA ANPOCS. GT39 Teoria política e pensamento político brasileiro - normatividade e história. Disponível em:<http://www.anpocs.org/portal/index.php?option=com_docman\&task=doc_view\&g $\mathrm{id}=9208 \&$ Itemid=456 $>$. Acesso em: 31 mai 2015.

RAWLS, John. Uma teoria da justiça. São Paulo: Martins Fontes, 2008.

ROUSSEAU, Jean Jacques. Do Contrato Social. São Paulo: Abril Cultural, 1983.

SEN, Amartya. Desenvolvimento como Liberdade. Trad. Laura Teixeira Motta. São Paulo: Companhia das Letras, 2000.

SILVA, José Afonso da. Curso de Direito Constitucional Positivo. São Paulo: Malheiros, 2003.

SOARES, Fabiana de Menezes. Direito administrativo de Participação. Belo Horizonte: Ed. Del Rey, 1997. 